\title{
Association and synergistic interaction between promoter variants of the $D R D 4$ gene in Japanese schizophrenics
}

\author{
Mizuho Nakajima $\cdot$ Eiji Hattori $\cdot$ Kazuo Yamada $\cdot$ Yoshimi Iwayama $\cdot$ \\ Tomoko Toyota $\cdot$ Yasuhide Iwata $\cdot$ Kenji J. Tsuchiya $\cdot$ Genichi Sugihara \\ Kenji Hashimoto · Hiroyuki Watanabe - Masaomi Iyo - Akinori Hoshika • \\ Takeo Yoshikawa
}

Received: 19 September 2006/ Accepted: 16 October 2006/Published online: 7 November 2006

(C) The Japan Society of Human Genetics and Springer 2006

\begin{abstract}
Recent association studies suggest that polymorphisms in the promoter and exon 1 upstream region of the dopamine D4 receptor (DRD4) gene play a functional role in the development of common psychiatric illnesses, although there are also conflicting results. In this study, we re-sequenced this region to identify all genomic variants, and tested them for association with schizophrenia. A total of 570 Japanese schizophrenic
\end{abstract}

The nucleotide polymorphism data reported is available in the DDBJ/EMBL/GenBank databases under the accession number ss61570833.

M. Nakajima $\cdot$ E. Hattori $\cdot$ K. Yamada .

Y. Iwayama $\cdot$ T. Toyota $\cdot$ T. Yoshikawa $(\bowtie)$

Laboratory for Molecular Psychiatry,

RIKEN Brain Science Institute, 2-1 Hirosawa,

Wako-city, Saitama 351-0198, Japan

e-mail: takeo@brain.riken.jp

M. Nakajima $\cdot$ A. Hoshika

Department of Paediatrics, Tokyo Medical University,

Shinjuku, Tokyo 160-0023, Japan

Y. Iwata $\cdot$ K. J. Tsuchiya $\cdot$ G. Sugihara

Department of Psychiatry and Neurology,

Hamamatsu University School of Medicine,

Hamamatsu, Shizuoka 431-3192, Japan

K. Hashimoto

Division of Clinical Neuroscience, Chiba University,

Center for Forensic Mental Health, Chiba 260-8670, Japan

H. Watanabe - M. Iyo

Department of Psychiatry, Chiba University,

Graduate School of Medicine, Chiba, Japan

T. Yoshikawa

CREST, Japan Science and Technology Agency, Saitama, Japan cases with matched controls were studied by genotyping all identified/validated common polymorphisms $(-1106 \mathrm{~T}>\mathrm{C},-906 \mathrm{~T}>\mathrm{C},-809 \mathrm{G}>\mathrm{A},-616 \mathrm{G}>\mathrm{C},-521 \mathrm{~T}>\mathrm{C}$, $-376 \mathrm{C}>\mathrm{T},-291 \mathrm{C}>\mathrm{T}$ and 12-bp repeat) and a known microsatellite (120-bp tandem duplication) in the upstream region. A single nucleotide polymorphism (SNP) $-809 \mathrm{G}>\mathrm{A}$ in the promoter region was found to be significantly associated with disease $(P=0.018$ and 0.032 for allelic and genotypic comparisons, respectively), although not surviving after Bonferroni correction. Logistic regression analysis showed that a combination of the four polymorphisms, $-809 \mathrm{G}>\mathrm{A},-616 \mathrm{G}>\mathrm{C},-291 \mathrm{C}>\mathrm{T}$ and the 12-bp repeat, conferred a susceptibility to schizophrenia. These results suggest that the upstream variants have a primary functional effect in the etiology of schizophrenia in the Japanese population.

Keywords Dopamine D4 receptor · Re-sequencing . Promoter region - Linkage disequilibrium - Haplotype block · Logistic regression analysis

\section{Introduction}

Disturbances in the dopamine neurotransmitter system have long been suggested to play a crucial role in the pathogenesis of schizophrenia (Prasad et al. 2002). However, involvement of dopamine-related genes in the manifestation of this disorder has been difficult to determine. The dopamine D4 receptor (DRD4) gene, located at chromosome 11p15.5 (Gelernter et al. 1992; Petronis et al. 1993), has received considerable interest because clozapine, a neuroleptic which is often effective against treatment-resistant symptoms, has a high affinity for this receptor (Sanyal and Van Tol 1997; 
Van Tol et al. 1991). Also, DRD4 is up-regulated in postmortem brain tissue from schizophrenic patients (Murray et al. 1995; Seeman et al. 1993; Stefanis et al. 1998; Sumiyoshi et al. 1995).

To investigate its genetic association with schizophrenia, many groups have examined polymorphisms of the DRD4 gene. Early studies focused on a 48-bp variable number of tandem repeat (VNTR) in exon 3. This tandem repeat comprises 2 (2R) to 11 (11R) 48-bp repeat units and codes for the third intracellular loop of the receptor protein (Van Tol et al. 1992). There is growing genetic evidence linking the VNTR with psychiatric traits or illnesses, such as novelty-seeking (Benjamin et al. 1996; Ebstein et al. 1996), attentiondeficit hyperactivity disorder (ADHD) (Faraone et al. 2001; LaHoste et al. 1996), and schizophrenia (Hwu et al. 1998; Jonsson et al. 1996; Kaiser et al. 2000; Sanak et al. 2005; Serretti et al. 2001), but the results are still variable.

In recent years, promoter region polymorphisms of the $D R D 4$ have also received particular attention because of their possible role in the regulation of gene transcription. To date, two polymorphisms in the promoter, $\mathrm{T}$ allele of the single nucleotide polymorphism (SNP) $-521 \mathrm{~T}>\mathrm{C}$ and a 120-bp tandem duplication (1.2 $\mathrm{kb}$ upstream from the initiation codon), are reported to reduce transcriptional efficiency (D'Souza et al. 2004; Okuyama et al. 1999). Numerous studies have examined the association of upstream (promoter region and exon 1) polymorphisms with schizophrenia and some have shown a positive association (Okuyama et al. 1999; Xing et al. 2003), although not all were in full agreement (Hong et al. 1998; Jonsson et al. 2001; Kohn et al. 1997; Lung et al. 2006; Mitsuyasu et al. 2001; Petronis et al. 1995).

Since previous studies focused primarily on individual polymorphisms, allelic heterogeneity and/or a relatively weak effect of the variants may partly explain these inconsistencies. When haplotype construction is difficult because of a weakness or absence of linkage disequilibrium (LD) in a genomic interval, as is the case for the promoter region of $D R D 4$, it may be important to test for a synergistic interaction between genetic variants in addition to performing single SNP analysis. Haplotype analysis is a reasonable strategy, assuming that the causative allele arises from a specific ancestral haplotype. However, this method is inadequate when there is an accumulation of multiple causative variants in a restricted genomic stretch. Additionally, haplotypic analysis is further compromised in regions where LD is decayed, because of the low statistical power to detect association due to inflated degrees of freedom. Therefore, clusters of potentially functional variants in genomic region with tenuous LD are better analyzed using a logistic regression framework that provides a powerful test of SNP etiology.

In this study, we examined the $5^{\prime}$ upstream region of $D R D 4$, by first re-sequencing the region to identify all genomic variants. We then tested the association of all identified/validated common variants individually, as well as performing synergistic interaction analyses between them and schizophrenia.

\section{Materials and methods}

Subjects

Samples from 570 unrelated cases of schizophrenia (285 men, 285 women; mean age $47.0 \pm 11.4$ years), and 570 age and sex matched controls (285 men, 285 women; mean age $46.7 \pm 11.1$ years) were analyzed. The diagnosis of schizophrenia was made by consultation according to DSM-IV criteria with consensus from at least two experienced psychiatrists. All available medical records were taken into consideration. Control subjects were recruited from hospital staff and volunteers who showed no evidence of present or past psychoses during brief interviews with psychiatrists. All subjects were from central Japan. The study was approved by the Ethics Committees of RIKEN, Hamamatsu University and Chiba University. All participants provided written informed consent.

Sequence analysis

The upstream region encompassing the promoter region and exon 1 of the DRD4 gene (from 1,216 bp upstream of "A" in the start codon to 293 bp downstream of this " $A$ ") was analyzed by the direct sequencing of PCR amplification from the genomic DNA of 30 unrelated Japanese schizophrenics. Primer sequences and detailed information on the reaction conditions are available upon request. Sequencing was performed using the DYEnamic ET terminator cycle sequencing kit (Amersham Biosciences, Piscataway, N.J., USA) and the ABI PRISM 3730 Genetic Analyzer (Applied Biosystems, Foster City, Calif., USA). Polymorphisms were detected by the SEQUENCHER program (Gene Codes Corporation, Ann Arbor, Mich., USA).

\section{Genotyping}

SNPs were typed by the TaqMan system (Applied Biosystems). PCR was performed using an ABI 9700 
thermocycler and fluorescent signals were analyzed by an ABI 7900 sequence detector single point measurement and SDS v2.0 software (Applied Biosystems). Conflicts or flagged alleles were resolved by re-genotyping. Two microsatellite marker loci, the 120-bp tandem duplication and the 12-bp repeat polymorphism (Fig. 1), were amplified by PCR using fluorescently labeled primers. PCR fragments were analyzed on an ABI PRISM 3730 Genetic Analyzer (Applied Biosystems). Genotypes were determined using GeneScan 3.5.2 and Genotyper 3.6 software (Applied Biosystems).

\section{Statistical analyses}

The allelic and genotypic distributions were tested for association by Fisher's exact test for biallelic markers (SNPs, the 120-bp tandem duplication and the 12-bp repeat polymorphism).

Haplotypic association analysis was performed using COCAPHASE in the UNPHASED package (http:// www.rfcgr.mrc.ac.uk/ fdudbrid/software/unphased/) (Dudbridge 2003). We employed a 2- and 3-marker sliding window analysis using COCAPHASE. To estimate the degree of LD between pairs of loci, the standardized disequilibrium coefficient $\left(D^{\prime}\right)$ was calculated and haplotype blocks were defined using the Haploview program (http://www.broad.mit.edu/mpg/ haploview/) (Barrett et al. 2005).

Logistic regression analysis

To test the multiple polymorphisms in the upstream region for a synergistic effect, stepwise logistic regression analysis was performed using the SPSS Software (Release 11.0J) (SPSS Japan, Tokyo, Japan). We employed a procedure of backward selection in which we started with all the markers genotyped in the present study. According to the approach of Cordell and Clayton (2002), we set dummy variables, $x_{1}$ and $x_{2}$, taking values $x_{1}=-1,0$ and $1, x_{2}=-0.5,0.5$ and -0.5 , for genotypes $\mathrm{w} / \mathrm{w}, \mathrm{w} / \mathrm{m}$ and $\mathrm{m} / \mathrm{m}$, respectively (w: wildtype, m: mutant).

\section{Results}

We re-sequenced the upstream region of the $D R D 4$ gene, and identified a total of eleven SNPs: $-1106 \mathrm{~T}>\mathrm{C}$, $-930 \mathrm{C}>\mathrm{G},-906 \mathrm{~T}>\mathrm{C},-873 \mathrm{G}>\mathrm{A},-809 \mathrm{G}>\mathrm{A},-616 \mathrm{G}>\mathrm{C}$, $-603 \mathrm{G}>\mathrm{T}, \quad-595 \mathrm{G}>\mathrm{del}, \quad-521 \mathrm{~T}>\mathrm{C}, \quad-376 \mathrm{C}>\mathrm{T}$, and $-291 \mathrm{C}>\mathrm{T}$, and a 12-bp repeat polymorphism (Fig. 1). One novel variant, $-930 \mathrm{C}>\mathrm{G}$ (deposited into GenBank as ss61570833), was detected in only 1 out of 58 chromosomes. The remaining variants were already present in the public databases and were validated in Japanese subjects during the course of this study.

The eight markers, $-1106 \mathrm{~T}>\mathrm{C},-906 \mathrm{~T}>\mathrm{C},-809 \mathrm{G}>\mathrm{A}$, $-616 \mathrm{G}>\mathrm{C},-521 \mathrm{~T}>\mathrm{C},-376 \mathrm{C}>\mathrm{T},-291 \mathrm{C}>\mathrm{T}$, and the 12-bp repeat polymorphism in exon 1 , were selected for genotyping using the criterion of a minor allele frequency $>0.05$ from our sequencing data. We also typed the size of the 120-bp tandem duplication (bi-allelic polymorphism with either one or two repeat alleles). The information on markers is shown in Table 1 . The 12-bp repeat polymorphism was mostly bi-allelic with the exception of four chromosomes (three from schizophrenics and one from controls) that contained a three-repeat allele.

Allelic and genotypic distributions of the promoter SNP $-809 \mathrm{G}>\mathrm{A}$ differed significantly between cases and controls $(P=0.018$ and 0.032 for allelic and genotypic comparisons, respectively). In the exploratory haplotype window analysis, the two-SNP haplotype

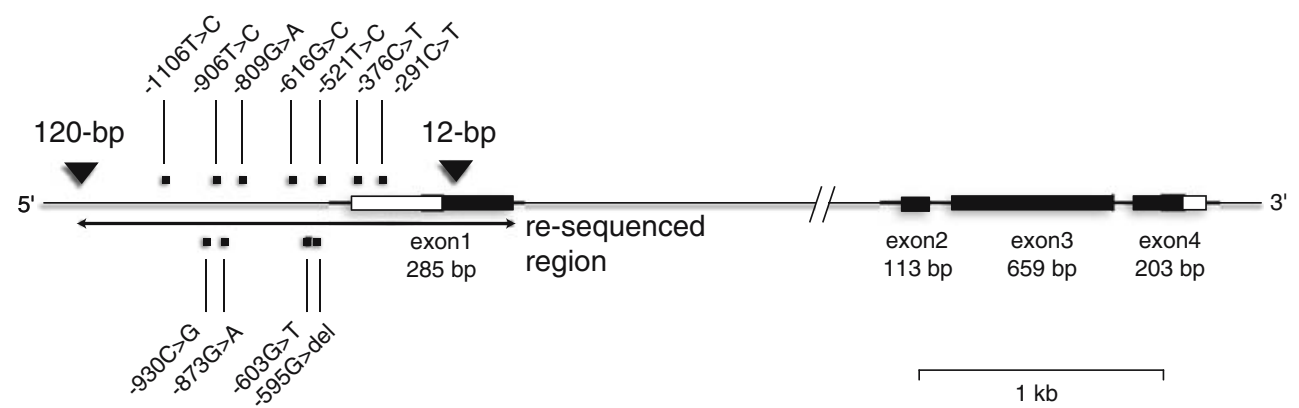

Fig. 1 Genomic structure and location of polymorphic sites within $D R D 4$. Exons are denoted by boxes, with untranslated regions in white and translated regions in black. The sizes of exons and a scale are also shown. SNPs and microsatellites are indicated by solid squares and triangles, respectively. Resequencing was performed on the upstream region (from $1.2 \mathrm{~kb}$ upstream of the initiation codon to the $3^{\prime}$ end of exon 1 ) 
Table 1 Genotype distributions of bi-allelic polymorphisms from the upstream region of DRD4

\begin{tabular}{|c|c|c|c|c|c|c|c|c|c|}
\hline \multirow{4}{*}{$\begin{array}{l}\text { Marker } \\
-1.2 \mathrm{~kb} \\
120 \text {-bp repeat }\end{array}$} & \multirow{2}{*}{$\begin{array}{l}\text { dbSNP } \\
\text { ID } \\
-\end{array}$} & \multirow{2}{*}{$\begin{array}{l}\text { Physical } \\
\text { position }\end{array}$} & \multirow{2}{*}{$\begin{array}{l}\text { Case or } \\
\text { control }\end{array}$} & \multirow[t]{2}{*}{$n$} & \multicolumn{3}{|c|}{ Genotype frequencies } & \multirow{2}{*}{$\begin{array}{l}P \text { value for } \\
\text { allelic } \\
\text { association }\end{array}$} & \multirow{2}{*}{$\begin{array}{l}P \text { value for } \\
\text { genotypic } \\
\text { association }\end{array}$} \\
\hline & & & & & $1 / 1$ & $1 / 2$ & $2 / 2$ & & \\
\hline & & & Case & 569 & 0.04 & 0.32 & 0.64 & 0.202 & 0.377 \\
\hline & & & Control & 570 & 0.06 & 0.34 & 0.61 & & \\
\hline \multirow[t]{3}{*}{$-1106 \mathrm{~T}>\mathrm{C}$} & rs936460 & 626199 & & & $\mathrm{~T} / \mathrm{T}$ & $\mathrm{T} / \mathrm{C}$ & $\mathrm{C} / \mathrm{C}$ & & \\
\hline & & & Case & 569 & 0.79 & 0.20 & 0.02 & 0.522 & 0.644 \\
\hline & & & Control & 570 & 0.76 & 0.22 & 0.02 & & \\
\hline \multirow[t]{3}{*}{$-906 \mathrm{~T}>\mathrm{C}$} & rs 3758653 & 626399 & & & $\mathrm{~T} / \mathrm{T}$ & $\mathrm{T} / \mathrm{C}$ & $\mathrm{C} / \mathrm{C}$ & & \\
\hline & & & Case & 569 & 0.66 & 0.31 & 0.03 & 0.116 & 0.223 \\
\hline & & & Control & 569 & 0.62 & 0.34 & 0.05 & & \\
\hline \multirow[t]{3}{*}{$-809 \mathrm{G}>\mathrm{A}$} & rs936461 & 626496 & & & $\mathrm{~A} / \mathrm{A}$ & $\mathrm{A} / \mathrm{G}$ & $\mathrm{G} / \mathrm{G}$ & & \\
\hline & & & Case & 562 & 0.03 & 0.33 & 0.64 & 0.018 & 0.032 \\
\hline & & & Control & 564 & 0.06 & 0.35 & 0.59 & & \\
\hline \multirow[t]{3}{*}{$-616 \mathrm{G}>\mathrm{C}$} & rs747302 & 626689 & & & $\mathrm{C} / \mathrm{C}$ & $\mathrm{C} / \mathrm{G}$ & $\mathrm{G} / \mathrm{G}$ & & \\
\hline & & & Case & 565 & 0.09 & 0.44 & 0.47 & 0.769 & 0.257 \\
\hline & & & Control & 568 & 0.10 & 0.39 & 0.50 & & \\
\hline \multirow[t]{3}{*}{$-521 \mathrm{~T}>\mathrm{C}$} & rs1800955 & 626784 & & & $\mathrm{~T} / \mathrm{T}$ & $\mathrm{T} / \mathrm{C}$ & $\mathrm{C} / \mathrm{C}$ & & \\
\hline & & & Case & 566 & 0.34 & 0.48 & 0.19 & 0.371 & 0.377 \\
\hline & & & Control & 569 & 0.34 & 0.50 & 0.16 & & \\
\hline \multirow[t]{3}{*}{$-376 \mathrm{C}>\mathrm{T}$} & rs916455 & 626929 & & & $\mathrm{~T} / \mathrm{T}$ & $\mathrm{T} / \mathrm{C}$ & $\mathrm{C} / \mathrm{C}$ & & \\
\hline & & & Case & 561 & 0.01 & 0.18 & 0.81 & 0.732 & 0.838 \\
\hline & & & Control & 562 & 0.01 & 0.19 & 0.80 & & \\
\hline \multirow[t]{3}{*}{$-291 \mathrm{C}>\mathrm{T}$} & rs916457 & 627014 & & & $\mathrm{~T} / \mathrm{T}$ & $\mathrm{T} / \mathrm{C}$ & $\mathrm{C} / \mathrm{C}$ & & \\
\hline & & & Case & 565 & 0.01 & 0.21 & 0.79 & 0.518 & 0.080 \\
\hline & & & Control & 566 & 0.02 & 0.19 & 0.79 & & \\
\hline & rs4646983 & $627392-627391$ & & & $1 / 1^{\mathrm{a}}$ & $1 / 2^{\mathrm{a}}$ & $2 / 2^{\mathrm{a}}$ & & \\
\hline \multirow[t]{2}{*}{12 -bp repeat } & & & Case & 568 & 0.02 & 0.25 & 0.73 & 0.512 & 0.248 \\
\hline & & & Control & 569 & 0.03 & 0.21 & 0.76 & & \\
\hline
\end{tabular}

$\bar{a}$ Alleles are coded by the number of repeats. Four subjects (three from the schizophrenia and one from the control group) with three repeats are omitted from this table. Significant results are shown in bold type

$[(-1106 \mathrm{C})-(-906 \mathrm{C})]$ tended to be over-represented in schizophrenia (frequencies in cases and in controls were 0.70 and 0.66 , respectively, $P=0.0656$ ) (data not shown).

In LD analysis, $D^{\prime}$ values were close to 1 in the distal [(120-bp repeat $)-(-1106 \mathrm{~T}>\mathrm{C})-(-906 \mathrm{~T}>\mathrm{C})]$ and proximal $[(-376 \mathrm{C}>\mathrm{T})-(-291 \mathrm{C}>\mathrm{T})-(-12-\mathrm{bp})]$ segments of the upstream region, with each defined as a haplotype block, but it did not hold for the region in between (Fig. 2). Decay of LD in this short stretch $(1.2 \mathrm{~kb})$ may imply a high local recombination rate. Therefore, in addition to conventional haplotypewindow analysis, we employed logistic regression analysis, which can test a combinatorial effect of multiple SNPs simultaneously. A combination of four polymorphisms $(-809 \mathrm{G}>\mathrm{A},-616 \mathrm{G}>\mathrm{C},-219 \mathrm{C}>\mathrm{T}$ and 12-bp repeat) appeared to affect susceptibility to schizophrenia (Table 2).

\section{Discussion}

In this study of the DRD4 gene, we focused on the upstream region, where associations with psychiatric phenotypes have been previously reported. However, genetic variants in this region do not show consistent association with schizophrenia. This may have been due to insufficient statistical power or inadequate interrogation of genomic variations in some studies. In addition, the differences in marker sets between studies increase the ambiguity when interpreting data. To minimize these problems, we adopted the thorough approach of re-sequencing and genotyping all validated polymorphisms.

Both upstream region variants, the single marker $-809 \mathrm{G}>\mathrm{A}$ and a multi-marker combination, displayed association with schizophrenia in this study. The SNP $-521 \mathrm{~T}>\mathrm{C}$, which was previously reported to show association with schizophrenia in an independent Japanese sample set (Okuyama et al. 1999), was not significant in our data set, as in other population data sets (Ambrosio et al. 2004; Jonsson et al. 2001; Segman et al. 2003). Since it is conceivable that particular combinations of multiple variants may confer an enhanced susceptibility to schizophrenia, we performed a logistic regression analysis to test all SNPs in the upstream region for association. This 


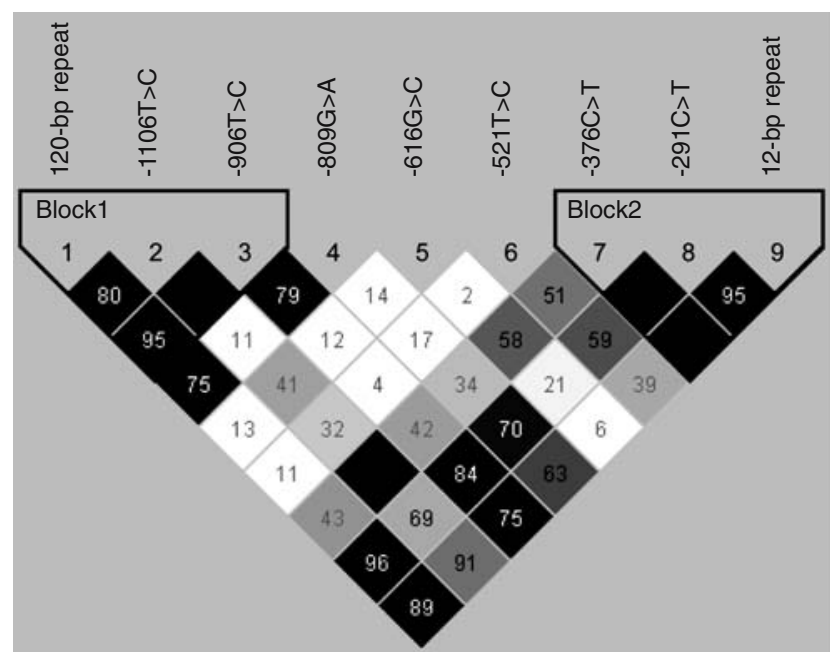

Fig. 2 Haplotype organization of DRD4 in Japanese. The haplotype block pattern was constructed by the Haploview program using the genotype data from both case and control samples (1,140 subjects). The number in each cell represents the LD parameter $D^{\prime}(\times 100)$, blank cells mean $D^{\prime}=1$. Each cell color is graduated relative to the strength of LD between markers, which is defined by both the $D^{\prime}$ value and confidence bounds on $D^{\prime}$. Strong LD was observed in the discrete distal [(120-bp repeat $)-(-1106 \mathrm{~T}>\mathrm{C})-(-906 \mathrm{~T}>\mathrm{C})]$ and proximal $[(-376 \mathrm{C}>\mathrm{T})-$ $(-291 \mathrm{C}>\mathrm{T})-(12-b p$ repeat $)]$ segments, but not in the intervening region

Table 2 Logistic regression analysis in the upstream region of DRD4

\begin{tabular}{lllllll}
\hline Marker & $\beta$ & SE & $\begin{array}{l}\text { Wald's } \\
\chi^{2}\end{array}$ & $\begin{array}{l}P \\
\text { value }\end{array}$ & OR & $\begin{array}{l}\text { OR 95\% } \\
\text { CI }\end{array}$ \\
\hline$-809 \mathrm{G}>\mathrm{A}$ & 0.346 & 0.127 & 7.384 & 0.007 & 1.414 & $1.10-1.82$ \\
$-616 \mathrm{G}>\mathrm{C}$ & 0.247 & 0.125 & 3.872 & 0.049 & 1.280 & $1.00-1.64$ \\
$-291 \mathrm{C}>\mathrm{T}$ & 1.031 & 0.400 & 6.649 & 0.010 & 2.804 & $1.28-6.24$ \\
12-bp repeat & -0.725 & 0.274 & 6.988 & 0.008 & 0.484 & $0.28-0.83$
\end{tabular}

$\beta$ Logistic regression coefficient in the model, $S E$ standard error of the coefficient, Wald $\chi^{2}$ Wald statistic to test significance of the coefficient, $O R$ the odds ratio, $C I 95 \%$ confidence interval of the odds ratio

approach may be more appropriate than conventional haplotype analysis, when examining the upstream region of the $D R D 4$ gene where there is evidence of LD decay in a relatively short genomic stretch and most markers do not correlate with each other. Results appear to indicate a synergistic interaction among the four promoter polymorphisms in the DRD4 gene. These results should be treated with caution since there are limitations to the present association study. Firstly, this is a case-control study, where false positive findings due to population stratification can occur. Analysis of this sample set using STRUCTURE software (Pritchard et al. 2000) detected no evidence of population stratification (Shimizu et al. 2006). To address this issue further, we also performed a transmission disequilibrium test. This testing failed to replicate the association of $-809 \mathrm{G}>\mathrm{A}$ in a sample set of 80 complete schizophrenic trios (data not shown). This sample size would have only a limited statistical power to detect true association. Secondly, the significance of the $-809 \mathrm{G}>\mathrm{A}$ polymorphism in the promoter region disappeared after Bonferroni correction for multiple testing. Thirdly, the sample size is obviously limited and so the insignificant result for $-521 \mathrm{~T}>\mathrm{C}$ needs to be interpreted cautiously. The sample size in this study had a power of 0.59 to detect a susceptibility variant with a relatively small effect (relative risk = 1.2 and 1.44 for heterozygotes and homozygotes, respectively), when the allele frequency is 0.41 . This frequency equals that of SNP $-521 \mathrm{C}$, whose association with schizophrenia has been previously reported (Purcell et al. 2003; Xing et al. 2003).

In conclusion, to our knowledge, this is the first study that highlights a possible combinatorial effect of promoter SNPs in the DRD4 gene. It will be interesting to determine whether this multi-marker association can be confirmed in independent data sets, where samples are well-defined in terms of clinical variables such as symptoms, age-at-onset, severity, medication type, and response to antipsychotic treatment. Furthermore, it will be important to examine the functional effects of variant combinations, to understand the mechanisms by which they increase or decrease susceptibility to schizophrenia.

Acknowledgments We thank the members of the Research Resource Center at the RIKEN Brain Science Institute for the sequencing and GeneScan typing service. This work was supported by RIKEN BSI Funds, Research on Brain Science Funds from the Ministry of Health Labor and Welfare, Grant-in Aid from the MEXT and CREST funds from the Japan Science and Technology Agency, Japan.

\section{References}

Ambrosio AM, Kennedy JL, Macciardi F, Barr C, Soares MJ, Oliveira CR, Pato CN (2004) No evidence of association or linkage disequilibrium between polymorphisms in the $5^{\prime}$ upstream and coding regions of the dopamine D4 receptor gene and schizophrenia in a Portuguese population. Am J Med Genet B Neuropsychiatr Genet 125:20-24

Barrett JC, Fry B, Maller J, Daly MJ (2005) Haploview: analysis and visualization of LD and haplotype maps. Bioinformatics 21:263-265

Benjamin J, Li L, Patterson C, Greenberg BD, Murphy DL, Hamer DH (1996) Population and familial association between the D4 dopamine receptor gene and measures of Novelty Seeking. Nat Genet 12:81-84 
Cordell HJ, Clayton DG (2002) A unified stepwise regression procedure for evaluating the relative effects of polymorphisms within a gene using case/control or family data: application to HLA in type 1 diabetes. Am J Hum Genet 70:124-141

D'Souza UM, Russ C, Tahir E, Mill J, McGuffin P, Asherson PJ, Craig IW (2004) Functional effects of a tandem duplication polymorphism in the $5^{\prime}$ flanking region of the $D R D 4$ gene. Biol Psychiatry 56:691-697

Dudbridge F (2003) Pedigree disequilibrium tests for multilocus haplotypes. Genet Epidemiol 25:115-121

Ebstein RP, Novick O, Umansky R, Priel B, Osher Y, Blaine D, Bennett ER, Nemanov L, Katz M, Belmaker RH (1996) Dopamine D4 receptor (D4DR) exon III polymorphism associated with the human personality trait of Novelty Seeking. Nat Genet 12:78-80

Faraone SV, Doyle AE, Mick E, Biederman J (2001) Metaanalysis of the association between the 7-repeat allele of the dopamine $\mathrm{D}(4)$ receptor gene and attention deficit hyperactivity disorder. Am J Psychiatry 158:1052-1057

Gelernter J, Kennedy JL, van Tol HH, Civelli O, Kidd KK (1992) The D4 dopamine receptor (DRD4) maps to distal 11 p close to HRAS. Genomics 13:208-210

Hong CJ, Chiu HJ, Chang YS, Sim CB (1998) Twelve-nucleotide repeat polymorphism of D4 dopamine receptor gene in Chinese familial schizophrenic patients. Biol Psychiatry 43:432-435

Hwu HG, Hong CJ, Lee YL, Lee PC, Lee SF (1998) Dopamine D4 receptor gene polymorphisms and neuroleptic response in schizophrenia. Biol Psychiatry 44:483-487

Jonsson E, Brene S, Geijer T, Terenius L, Tylec A, Persson ML, Sedvall G (1996) A search for association between schizophrenia and dopamine-related alleles. Eur Arch Psychiatry Clin Neurosci 246:297-304

Jonsson EG, Ivo R, Forslund K, Mattila-Evenden M, Rylander G, Cichon S, Propping P, Nothen MM, Asberg M, Sedvall GC (2001) No association between a promoter dopamine $\mathrm{D}(4)$ receptor gene variant and schizophrenia. Am J Med Genet 105:525-528

Kaiser R, Konneker M, Henneken M, Dettling M, MullerOerlinghausen B, Roots I, Brockmoller J (2000) Dopamine D4 receptor 48-bp repeat polymorphism: no association with response to antipsychotic treatment, but association with catatonic schizophrenia. Mol Psychiatry 5:418-424

Kohn Y, Ebstein RP, Heresco-Levy U, Shapira B, Nemanov L, Gritsenko I, Avnon M, Lerer B (1997) Dopamine D4 receptor gene polymorphisms: relation to ethnicity, no association with schizophrenia and response to clozapine in Israeli subjects. Eur Neuropsychopharmacol 7:39-43

LaHoste GJ, Swanson JM, Wigal SB, Glabe C, Wigal T, King N, Kennedy JL (1996) Dopamine D4 receptor gene polymorphism is associated with attention deficit hyperactivity disorder. Mol Psychiatry 1:121-124

Lung FW, Chen N, Shu BC (2006) Dopamine D4 receptor gene and the $-521 \mathrm{C}>\mathrm{T}$ polymorphism of the upstream region of the dopamine D4 receptor gene in schizophrenia. Psychiatr Genet 16:139-143

Mitsuyasu H, Hirata N, Sakai Y, Shibata H, Takeda Y, Ninomiya H, Kawasaki H, Tashiro N, Fukumaki Y (2001) Association analysis of polymorphisms in the upstream region of the human dopamine D4 receptor gene (DRD4) with schizophrenia and personality traits. J Hum Genet 46:26-31

Murray AM, Hyde TM, Knable MB, Herman MM, Bigelow LB, Carter JM, Weinberger DR, Kleinman JE (1995) Distribution of putative D4 dopamine receptors in postmortem striatum from patients with schizophrenia. J Neurosci 15:2186-2191

Okuyama Y, Ishiguro H, Toru M, Arinami T (1999) A genetic polymorphism in the promoter region of DRD4 associated with expression and schizophrenia. Biochem Biophys Res Commun 258:292-295

Petronis A, Van Tol HH, Lichter JB, Livak KJ, Kennedy JL (1993) The D4 dopamine receptor gene maps on 11p proximal to HRAS. Genomics 18:161-163

Petronis A, Macciardi F, Athanassiades A, Paterson AD, Verga M, Meltzer HY, Cola P, Buchanan JA, Van Tol HH, Kennedy JL (1995) Association study between the dopamine D4 receptor gene and schizophrenia. Am J Med Genet 60:452-455

Prasad S, Semwal P, Deshpande S, Bhatia T, Nimgaonkar VL, Thelma BK (2002) Molecular genetics of schizophrenia: past, present and future. J Biosci 27:35-52

Pritchard JK, Stephens M, Donnelly P (2000) Inference of population structure using multilocus genotype data. Genetics 155:945-959

Purcell S, Cherny SS, Sham PC (2003) Genetic power calculator: design of linkage and association genetic mapping studies of complex traits. Bioinformatics 19:149-150

Sanak M, Zelek-Molik A, Nalepa I, Wegrzyn J, Wciorka J (2005) The dopamine D4 receptor VNTR in Polish schizophrenia patients. Schizophr Res 73:129-131

Sanyal S, Van Tol HH (1997) Review the role of dopamine D4 receptors in schizophrenia and antipsychotic action. J Psychiatr Res 31:219-232

Seeman P, Guan HC, Van Tol HH (1993) Dopamine D4 receptors elevated in schizophrenia. Nature 365:441-445

Segman RH, Goltser T, Heresco-Levy U, Finkel B, Shalem R, Schlafman M, Yakir A, Greenberg D, Strous R, Lerner A, Shelevoy A, Lerer B (2003) Association of dopaminergic and serotonergic genes with tardive dyskinesia in patients with chronic schizophrenia. Pharmacogenomics J 3:277-283

Serretti A, Lilli R, Lorenzi C, Lattuada E, Smeraldi E (2001) $D R D 4$ exon 3 variants associated with delusional symptomatology in major psychoses: a study on 2,011 affected subjects. Am J Med Genet 105:283-290

Shimizu H, Iwayama Y, Yamada K, Toyota T, Minabe Y, Nakamura K, Nakajima M, Hattori E, Mori N, Osumi N, Yoshikawa T (2006) Genetic and expression analyses of the STOP (MAP6) gene in schizophrenia. Schizophr Res 84:244-252

Stefanis NC, Bresnick JN, Kerwin RW, Schofield WN, McAllister G (1998) Elevation of D4 dopamine receptor mRNA in postmortem schizophrenic brain. Brain Res Mol Brain Res 53:112-119

Sumiyoshi T, Stockmeier CA, Overholser JC, Thompson PA, Meltzer HY (1995) Dopamine D4 receptors and effects of guanine nucleotides on $[3 \mathrm{H}]$ raclopride binding in postmortem caudate nucleus of subjects with schizophrenia or major depression. Brain Res 681:109-116

Van Tol HH, Bunzow JR, Guan HC, Sunahara RK, Seeman P, Niznik HB, Civelli O (1991) Cloning of the gene for a human dopamine D4 receptor with high affinity for the antipsychotic clozapine. Nature 350:610-614

Van Tol HH, Wu CM, Guan HC, Ohara K, Bunzow JR, Civelli O, Kennedy J, Seeman P, Niznik HB, Jovanovic V (1992) Multiple dopamine D4 receptor variants in the human population. Nature 358:149-152

Xing QH, Wu SN, Lin ZG, Li HF, Yang JD, Feng GY, Wang MT, Yang WW, He L (2003) Association analysis of polymorphisms in the upstream region of the human dopamine D4 receptor gene in schizophrenia. Schizophr Res 65:9-14 